\title{
A psychophysical method for assessing visual and acoustic hyperaesthesia in patients with mild head injury
}

Citation for published version (APA):

Bohnen, N., Twijnstra, A., Kroeze, J., \& Jolles, J. (1991). A psychophysical method for assessing visual and acoustic hyperaesthesia in patients with mild head injury. British Journal of Psychiatry, 159(6), 860863. https://doi.org/10.1192/bjp.159.6.860

Document status and date:

Published: 01/01/1991

DOI:

10.1192/bjp.159.6.860

Document Version:

Publisher's PDF, also known as Version of record

\section{Please check the document version of this publication:}

- A submitted manuscript is the version of the article upon submission and before peer-review. There can be important differences between the submitted version and the official published version of record.

People interested in the research are advised to contact the author for the final version of the publication, or visit the DOI to the publisher's website.

- The final author version and the galley proof are versions of the publication after peer review.

- The final published version features the final layout of the paper including the volume, issue and page numbers.

Link to publication

\footnotetext{
General rights rights.

- You may freely distribute the URL identifying the publication in the public portal. please follow below link for the End User Agreement:

www.umlib.nl/taverne-license

Take down policy

If you believe that this document breaches copyright please contact us at:

repository@maastrichtuniversity.nl

providing details and we will investigate your claim.
}

Copyright and moral rights for the publications made accessible in the public portal are retained by the authors and/or other copyright owners and it is a condition of accessing publications that users recognise and abide by the legal requirements associated with these

- Users may download and print one copy of any publication from the public portal for the purpose of private study or research.

- You may not further distribute the material or use it for any profit-making activity or commercial gain

If the publication is distributed under the terms of Article $25 \mathrm{fa}$ of the Dutch Copyright Act, indicated by the "Taverne" license above, 


\title{
A Psychophysical Method for Assessing Visual and Acoustic Hyperaesthesia in Patients with Mild Head Injury
}

\author{
N. BOHNEN, A. TWIJNSTRA, J. KROEZE and J. JQLLES
}

\begin{abstract}
Although it is well known that patients with mild head injury (MHII) are less able to ondure intense light and sound stimull than normal people, there are few psycho. physical studiess that have objectively measured this ype of hyperaesthesia. In the present study, using a computerised rating scale technique, both the maximal and submaximal levels of reduced tolerance to light and sound were assessed for a wide range of stimuli. Three to silx days after the trauma, 40 MHI patients were significantly less tolerant to stimuli of intensities over $71 \mathrm{~dB}$ and 500 lux levels than controls. These intensities are common, and MHI patients may suffer as a consequence.

British Journal of Psychiatry (1991), 159, 860-863
\end{abstract}

The post-concussional syndrome (PCS) tefers to a number of symptoms and signs that may occur singly or in combination after usually minor head injury (MHI). These symptoms are a mixture of quasiorganic and subjective symptoms, such as headache, dizziness, tiredness, insomnia, lowered tolerance to noise and light, irritability and difficulties with memory or concentration. There is disagreement in the literature between those who argue for a physiological pathogenesis and those who favour a psychological pathogenesis (Binder, 1986; Lishman, 1988). A subjective and invaliding symptom is the Jowered tolerance to intense light and sound stimuli. There are few psychophysical studies that have studied this type of hyperaesthesia (e.g. Jonsson et al, 1967; Waddell \& Gronwall, 1984). As an example of so-called organic evidence, Waddell \& Gronwall (1984) tested tolerance to light and sound on a more objective basis and demonstrated that, one to three weeks after injury, MHI patients hat a significantly lower threshold of tolerance to light and a slightly decreased tollerance to sound than healthy controls. In addition, they found no relationship between the subjective ratings and the objectively assessed levels of reduced tolerance. Moreover, it appeared that the number of objectively demonstrated deficits was larger than the number of spontaneous complaints.

The psychophysical studies performed so far (Jonsson et al, 1967; Waddell \& Gronwali, 1984) measured the maximal level or threshold of reduced tolerance to an increasing intensity of sound and light, but did not provide information on submaximal levels of lowered tolerance. The present study describes another method of assessing tolerance to light and sound on a more objective basis. This method not only measures the maximal level of reduced tolerance, but can also be used to compare the submaximal levels of lowered tolerance by applying a graded tolerance scale for each stimulus.

A major problem in the literature is the controversial use of psychophysical terms. Lowered tolerance has often been confused with sensitivity and hypersensitivity to light and sound. For reasons of clarity, only the term "tolerance' will be used in this article and is defined as the subjective ability to endure higher intensities of light and sound stimuli. In contrast, sensitivity and hypersensitivity refer to absolute or relative perception and thresholds of perception (Boff et al, 1986).

It was the airn of the present study to compare the maximal and submaximal levels of reduced tolerance to light and sound stimuli of MHI patients with those of matched healthy controls.

\section{Method}

Light and sound stimuli of five different intensities were presented using a computer. A personal computer with a parallel interface controlled both a tone generator (calibrated for $1000 \mathrm{~Hz}$ ) with varying amplitude and a $50 \mathrm{~W}$ ungstenhalogen lamp. The tone generator was connected to a pair of ATH-910 earphones (A.udiotechnica) with noise-reducing caps. The 50 W incandescent lamp was placed in a round tube. The glass-covered aperture (10 $\mathrm{cm}$ in diameter) was surrounded by a black ring and the tube was mounted on a mobile and adjustable stand.

Five intensities of sound and light were chosen on the empirical basis that they could be clearly distinguished by the human ear and eye $(57,71,81,89,95 \mathrm{~dB}$ for sound and $440,500,600,1000,1500$ lux for light). Each of the five intensities was randomly presented eight times; there were separate sessions for the two types of stimuli. Thus, each subject received a total of 40 stimuli for each sound and light session. Each stinulus was presented for four seconds, and was followed by a constant interval. The rise-fall time of the physical stimulus was greater than $10 \mathrm{~ms}$. The interval was kept constant in order to achieve a relative constancy in individual habitwation processes (for sound 6 seconds and for light 12 seconds; see also Stevens \& Stevens, 1963; Boff et al, 1986). During this interval, the 

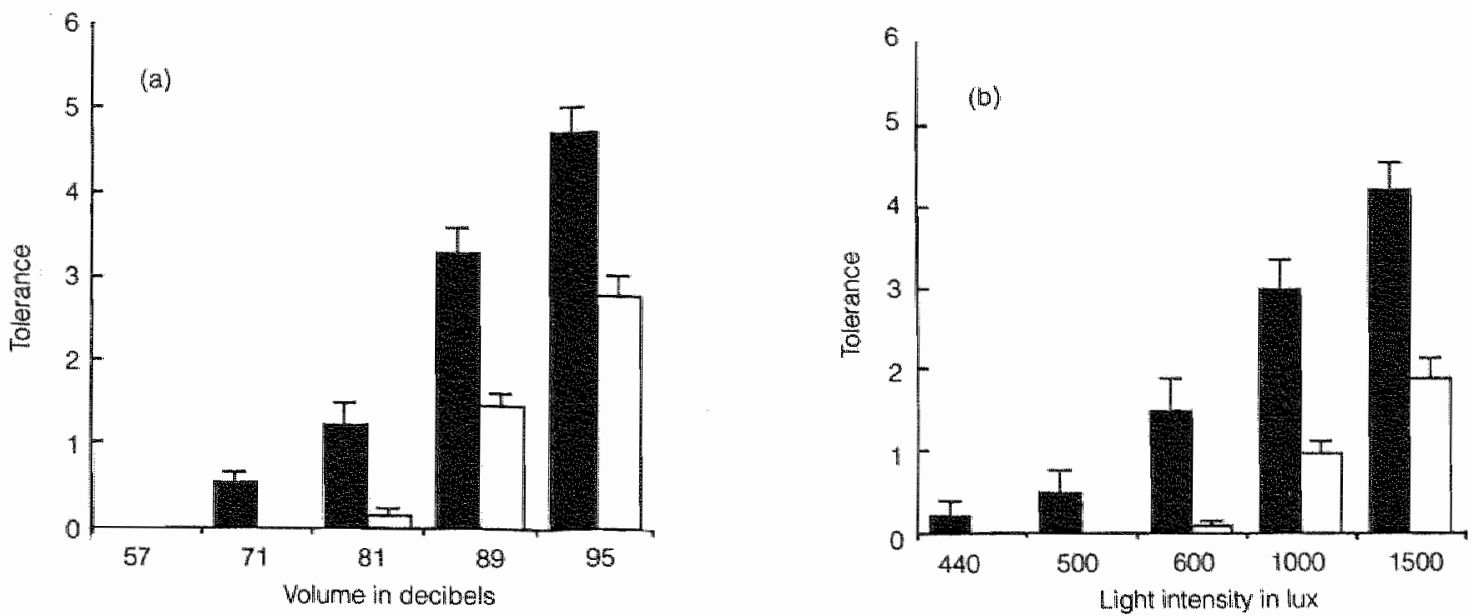

Fig. I Mean levels of tolerance of the patient ( $)$ and control ( $\square$ ) groups per intensity of (a) sound and (b) light (neans \pm s.e.m.) $(0=$ completely tolerant; $6=$ completely unbearable).

subject was asked to evaluate the preceding stimulus on a severn-point rating scale, ranging from totally bearable/ tolerant (score: s0), via very mildly (s1), mildly ( 22 ), moderately (s3), moderately to severely (s4), severely (s5) to totally unbearable ( 56 ). The response was given by pressing a button on a seven-point key board. After the session, the median tolerance value was calculated for each intensity. These median values were used for statistical analysis.

The minimum levels of noise in the examination room were in the range 46 to $51 \mathrm{~dB}$. Before putting on the earphones, the subject received the following instructions:

\footnotetext{
"You will hear a sertes of sounds of varying intensity through your headphones. Each sound will be presented for four seconds. After the tone has finished, please press the button on the seven. point key board that corresponds to the degree of tolerance you have experienced. The left button means that you can tolerate the sound stimulus, the one on the extreme right means that you find the sound unbearable. The buttons in-between correspond to a decreasing scalle of tolerance from left to right. A new stimulus will be presented automatically after six seconds. Forly stimuli of mixed intensity will be given at random."
}

The average background illumination in the examination room was about 300 lux with dimmed windows. Each. subject was seated so as to look into the centre of the light source at one metre distance from their eyes. The subjects received the following instructions:

"Look into the centre of the lamp. The larnp will shine for four seconds. You will then have 12 seconds to press a button on this seven-point key board that correspords to the degree of tolerance you hawe experienced. The left button means that you cam tolerate the light stimulus, the one on the extreme right means that you find the light urgearable. The buttons in between correspond to a decreasing scale of tolerance from left to right. Each new stimulus will be presented automatically after 12 seconds. Forty stimull of different intensity will the given at random."

Twenty patients ( 11 male, 9 female) with $\mathrm{MHI}$, who were not selected on the basis of post-concussional symptoms, were recruited from the Accident and Emergency Department of the Universal Hospital of Maastricht. All subjects had been unconscious for a period ranging from several seconds to 15 minutes; post-traumatic amnesia had lasted for less than 60 minutes. The EMV (Glasgow Coma) score for each patient on admission was 15 . None of the patients had evidence of a focal meurological deficit, and none had evidence of a skull fracture. Patients were excluded if they had consumed alcolhol at the time of the accident or if they had a history of pre-exilsting emotional problems. In addition, patients with hearing and visual problems were not eligible. The patients were tested three to six days after the trauma. The mean age was 26.4 (s.d.11.2) years. Only two patients were totally free from symptoms (in terms of headache and dizziness) at the time of testing.

The patients were matched with paid control subjects for sex, agge (plus or minus three years) and educational level (plus or minus one levell. The educational level was assessed using the scale of Verhage (1964), which has seven categories based on the nature and duration of education in the Netherlands. The control subjects ( $n=20$; mean age 26.9 (s.d. 12.3) years) had not been exposed to risk factors for brain dysifunction, such as brain trauma or a neuropsychiatric history. Informed consent was obtained from all subjects.

The first step in the statistical analysis was to assess whether there was an overall difference between the two groups for all the five intensities of light and sound. Because of the ordinal level of the rating scale, the ranks ower all observations per intensity were calculated (Conover \& Iman, 1981) and were analysed by multivariate analysis of variance (MANOVA; SAS, 1985). In the second step, separate analyses per intensity were carried out using Wilcoxor's rank sum test. A probability level of less than 0.05 defined a significant difference.

\section{Results}

There was an overall significant difference between the tolerance of MHI patients and controls to both sound 
(Wilk's lambda: $F(5,34)=6.84, P<0.001)$ and to light (Wilk"s lambda: $F(5,34)=6,64, P<0,001)$ (Fig. 1). Separate Wilcoxon tests per intensily indicated that the MHL patients tolerated the $71,(z=2.1, P<0.05)$, $81(z=3.1, P<0.01)$, $89(z=3.9, P<0.001)$ and $95(z=4.1, P<0.001) \mathrm{dB}$, and the $500(z=2.6, P<0.01), 600(z=3.5, p<0.001), 1000$ $(z=4.1, P<0.001)$ and $1500(z=4,3, P<0.001)$ lux lewels significantly less well than the control subjects.

None of the controls demonstrated a severely to totally reduced level of tolerance (score 5-6) to any of the light and sonnd stimull. In contrast, there were 13 patients $(n=20)$ who had a severely to totally reduced level of tolerance $(55-6)$ to $95 \mathrm{~dB}$, and nine patients to 1500 lux.

\section{Discussion}

Jonsson et al (1967) found that MHI patients with persistent post-concussional symptoms had a significantly lower ability to endure intense sound and light stimuli than healthy controls. However, their results should be considered with some caution, as the study did not include MHI patients without post-concussional symptoms. Waddell \& Gronwall (1984) found that the mean luminance tolerated by a select group of MHI patients one to three weeks after the trauma (1366 lux) was significantly lower than that tolerated by controls (1783 lux). Although the mean sound intensity tolerated by the same patients $(82 \mathrm{~dB})$ was also lower than that tolerated by controls $(94 \mathrm{~dB})$, this difference was not significant.

Using the method described, we found that not only tolerance to light, but also tolerance to sound, was significantly decreased in MHI patients compared with the tolerance of matched controls. With respect to submaximal levels of reduced tolerance to less intense stimuli, MHI patients were significantly less tolerant to low sound $(71 \mathrm{~dB})$ and light intensities ( 500 lux) than healthy controls. This means that, for example, the shining of a lamp or the noise of traffic could disturb a MHI patient. With respect to the presence of subjective post-concussional symptoms, it was striking that the two patients who had no subjective complaints at the time of testing were also more tolerant to the stimuli.

The finding of Waddell \& Gronwall (1984) that lowered tolerance to light and sound reported subjectively, was unrelated to objectively demonstrated deficits, suggests that an objective basis for such complaints exists even though these symptoms are not always reported. Moreover, Jonsson et al (1967) found that in contrast to reported neurasthenic complaints, MH』 patients with persistent symptoms one to three months after the trauma had a decreased tolerance to light and sound in comparison with neurotic control patients.

The experimental data available at present do not give a clear indication of how the visual and auditory system changes in MHI patients. Sensory data from receptors must be screened, filtered and evaluated under the control of higher cortical centres, including the prefrontal cortex and the limbic system. The reciprocal connectivity of the prefrontal cortex with several areas of the sensory and parasensory association cortex is especially abundant in primates (Fuster, 1989). While traumatic brain injury mainly affects the brain diffusely (Alexander, 1982), Walsh (1987) has noted that the frontal and temporal lobes are particularly vulnerable because of the way they rest against the base of the skull. Taken together, it seems quite plausible that the changes in tolerance to light and sound are a manifestation of a lack of inhibitory control by orbital frontal cortex areas over sensory information processed by posterior brain areas and subcortical centres. More research is needed to evaluate this notion more fully. With respect to other concepts in psychophysics, there is no clear information at the moment about the relationships between tolerance versus (hyper)sensitivity and subjective loudness or brightness.

The present results indicate that the tolerance of MHI patients to light and sound is a gradual rather than a threshold phenomenon. Tolerance decreases with increasing intensity levels. MHI patients may already be disturbed by intensity levels of sound or light common to daily life in an early phase after the trauma. Further research is aimed at investigating the tolerance of patients with persistent post-traumatic symptoms to light and sound in order to evaluate the organic basis of persistent PCS.

\section{Acknowledgements}

The authors thank Germa Wijnen, Hub Hamers and Peter Houx for technical assistance, and the staff of the Department of Neurology for its co-operation in performing the study.

\section{References}

Al.exmander, M. P. (1982) "Traluniatic brain injury. In Psychiatric Aspects of Neurologic Disease, vol. Il (eds D. F. Benson \& D. Blumer), pp. 219-250. New York: Grune \& Stratton.

Bumber, L. M. (1986) Persisting symptoms after mild head injury: a review of the postconcussive syndrome. Journal of Clinical and Etperimental Neuropsychology, 8, 323-346.

BOFE, K. R., KAUUMAN, L. THOMAS, J. P. (1986) Handbook of Percepion and Hituman Perfornance. Volume I" Semsory Processes and Perception. New York: John Wiley.

Conovien, W. I. \& IMAN, R. L. (1981) Rank transformations as a bridge between parametric and nonparametric statistics. American Statisticiam, 35, 124- 129 .

Fuster, J. M. (1989) The Prefromial Cortex (2nd edn). New York: Raven Press.

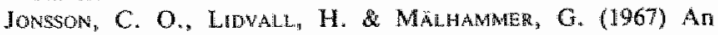
exploratory psychological study of the post-tranmatic cerebral syndrome. Acta Newrologica Scandirnavica, 43, 158-166. 
LishMAn, W. A. (1988) Physiogenesis and psychogenesiss in the "post-concussional symdrome". Britist Journal of Psychiorry, $153,460-469$.

SAS (1985) Statistics (Wersion 5 wa). Cary: SAS.

STEvers, J. C. \& STEVENS, S. S. (1963) Bughthess function: effects of adaptation. Joumal of the Optical Sowiery of Anterica, 55, 375-385.

VERHAG, R. (1964) Intethgertie en lefind. PhD Dissertation. Assen, The Netherlands.

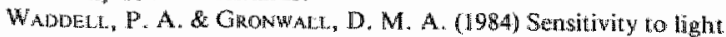
and sound following minor thead injury. Acta Neurologica Scandinawica, 69, 270-276.

Walsh, K. W. (1987) Neuropsychology: a Chical Approach. New York: Livingston.
* N. Bohnen, MD, PhD, Department of Neuropsychology of Psychobiology, University of Limburg, PO Box 616, 6200 MD Maasmicht, The Netherland's; A. Twijnstra, MD, $\mathrm{PD}$, Depariment of Neurology, University Hospital of Macsichich; J. Kroeze, PhD, Psychophysicist, Laboratory of Psychology, University of Utrecht, The Netherlands; J. Jolles, PhD, Professor of Neuropsychology and Biopsychology, University of Limburg, Maasiricht

* Correspondence

\title{
Seasonal Affective Disorder in Adolescence
}

\author{
CHRISTOPHER PAUL LUCAS
}

\begin{abstract}
Two adolescent girls with seasonal affective disorder (SAD) are described. It is suggested that the classic symptom profile seen in adults is not characteristic in younger subjects. Although hypersomnia is prominent, increased appetite and carbohydrate craving are rarely reported. Local meteorological data link the course of the disorder in one case to the hours of sunshine and ambient ternperature during the winter months.
\end{abstract}

British Journal of Psychiatry (1991), 159, 863-865

The first report of a patient with seasonal mood cycles and the treatment of these with bright-light therapy was by Lewy et al (1982). The description of the currently accepted syndrome of SAD was later made, in a group of patients, by Rosenthal et al (1984).

SAD is commonly defined as a clinically significant. affective disorder occurring in a particular season (usually winter), on a regular basis, with relative absence of symptoms at other times. DSM-III-R (American Psychiatric Association, 1987) requires three episodes of major depression (two in consecutive years), and for the seasonal episodes to outnumber non-seasonal ones by $3: 1$. Clinic-based studies have shown that one-fifth of patients with recurrent depression have a winter seasonal pattern to their disorder (Garvey et al, 1988).

The clinical picture of depression which occurs primarily during the winter months has been shown to differ from non-seasonal recurrent depression (Garvey et al, 1988). In most patients, appetite increases during the depressive period and many describe crawing carbohydrate-rich foods. Hypersomnia is very common, with most subjects going to sleep earlier and waking up later. Most patients report drowsiness throughout the day, with the late afternoon being a time of especially low energy and mood (e.g. Winton \& Checkley, 1989).
The existence of $\mathrm{SAD}$ as a discrete clinical entity has been questioned by Eastwood et al (1988) who feel that it represents an uncommon condition in a self-selected sample or something so mild as not ordinarily to come to the attention of doctors.

The hypothesis that researchers are more likely to recruit subjects who conform to their pre-existing ideas about the clinical picture, and that this may be a particular problem when subjects are contacted via media advertisements, was tested by Thompson (1989). In a well designed study, no significant differences in clinical features were found whether patients entered the study via referral from consultant psychiatrists or by self-referral in response to newspaper or television advertisements.

In a two-stage survey, which looked at the extent and severity of seasonally associated symptoms in the general population, almost half of the subjects questioned related feeling worst in the months of January and/or February and this bore an apparent relationship to ambient temperature and photoperiod (Kasper et al, 1989a). A quarter of those questioned felt that seasonal mood changes were a significant problem. The prevalence rate for SAD (as defined in the study) was estimated at $4.5 \%$.

Full-spectrum (bright-light) therapy has been found to have a specific effect on the characteristic symptoms of SAD (Yerevanian et $a l$, 1986). In placebo-controlled trials, marked reduction in scores on a modified Hamilton observer rating scale (which included observer ratings of the atypical depressive symptoms of SAD and self-rating scales) have been demonstrated (e.g. Rosenthal et al, 1989). Studies have also shown that light therapy has a significant effect on symptoms in patients with only mildmoderate impairment, the so-called "sub-syndromal. seasonal affective disorder' (Kasper et al, 1989b). 